\title{
Maintaining the course, with changes
}

We are starting a new year and some adjustments in the Brazilian Annals of Dermatology will be made to improve the dissemination of our articles.

A new section (Epidemiology and Biostatistics Applied to Dermatology) will be launched regarding the epidemiological and methodological aspects of research. Our goal is to provide a discussion of conceptual elements and assist in the operationalization of authors and readers of our journal, both in project execution, as in the critical reading of articles in general. We believe that as the process of research elaboration is better understood, an increase in scientific quality will be provided for all. Thus, an article about the correct manner to enter data on tables and graphs will be inaugurating this section on the second issue of our journal in 2014.

Filling the gap with this kind of information for authors and readers, in addition to the citation of articles that will be published in this section, will contribute to an even wider diffusion of the growing positive concept that $\mathrm{ABD}$ has been garnering in recent years, and may also influence the rates of impact measuring indexes.

Among the new features, we also communicate that for technical indexing reasons, the sections "Iconography" and "What is your diagnosis", will be extinguished. On the other hand, we would like to announce that we will encourage the publication of articles in the "Letters" section, which will replace the "Correspondence" section and should accommodate most succinct clinical cases with greater agility of publication, among other possibilities.

All these innovations, with the new standards for publications will be available on the journal's website from January 2014.

Finally, the editors of the ABD would like to thank all those who believe in the project to keep strong, and ever more prestigious, the main vehicle of scientific dissemination of the Brazilian Dermatology, which is now well-established in the Latin American and world literature.

\author{
Renan Rangel Bonamigo \\ Associate Editor \\ Anais Brasileiros de Dermatologia \\ (Annals of Brazilian Dermatology)
}

